In so many ways it's an incredibly banal thing to note, but for me at least it really wasn't until I was reading a book on the subject did I realise nudity is everywhere. Sure, there's the fetishisation of nubile young bodies in advertising; the salacious comments about nudism and peoples' mixed experiences of nudist beaches; the nude in art; and the nakedness (in its many guises) of sex, streakers, and the daily rituals of (de)robing we generally all experience. Further, due to the

\section{uncovering nudity}

RUTH BARCAN

Nudity: A Cultural Anatomy

Berg, Oxford, 2004

ISBN 1-85973-872-9

RRP $\$ 69.00$ (pb) contentious standing of public nudity in con-

temporary Western societies (the specific focus of this book) and its association with sexuality, it does of course constantly feature in news reporting. My reading of the book coincided with a number of media reports which registered perhaps more than they would otherwise: the damaging in a drunken pub incident in Melbourne of the landmark Young and Jackson Hotel's famous nude 'Chloe' (the painting itself gets a mention on page 31 ); the proclamation of Dame Helen Mirren as 'naturist of the year' by peak British group British Naturism; and, most worryingly, reports from Swaziland that bus drivers were apparently taking it upon themselves to sexually assault young women wearing mini-skirts, following a ban issued by some drivers earlier in the year. Certainly, Nudity: A Cultural Anatomy definitely gets you thinking about how nudity, or the relative perception of it, is indeed a foundational point of organisation for the Judeo-Christian world.

Wishing to move beyond the already relatively charted examination of nakedness and representation (Ruth Barcan especially draws attention to the oft-explored figure of the 'nude' 
in the 'implicitly masculinist visual arts tradition as viewed by the Western world view-in order in Western art' (5) and in the feminist cultural to further elaborate upon the meaning of nakedcriticism of pornography and theorising of the ness within this Western paradigm. In so doing, 'male gaze'), Barcan's focus in Nudity is also some of the most fundamental ordering belief upon the actual embodied experience of naked- structures can be revealed in terms of the role ness, bodily adornment practices and relative of clothing within this ideological system; undress. Given the breadth of issues such an namely, clothing as being inextricably bound to examination necessarily involves, Barcan offers humanness and 'civilization', with obvious ramiwhat she refers to as a 'horizontal' rather than fications for the reading of various unclothed 'vertical' study in order to accommodate wider 'others' (indigenous peoples, the 'uncivilised', coverage of a hitherto under-explored area. 'deviant' or 'insane').

What this means for the reader is that while Chapter 1 sets the philosophical groundwork they may at times be left wanting a deeper for the rest of the book by exploring nakedness/ analysis on particular topics, Nudity can lay dress as a complex dichotomy mobilised some claim to being if not an exhaustive study, variously depending upon the needs and beliefs then certainly a thorough and entertaining of the discursive community. To begin with, a overview of the field—one which gives rise to series of epistemological binary structures further questions perhaps, but that provides a are identified:

solid philosophical foundation from which to nakedness clothing

explore more specific issues.

Setting up this philosophical terrain, the book explicitly concerns itself with nudity within what the author refers to as the Western tradition and from here it focuses on two core metaphysical traditions that it is argued provide the foundation for Christian approaches to the natural cultural unchanging changeable invisible visible truth lies

pure corrupt

human nature human society

pre-, non-, antisocial social. (14)

body: Platonic and Jewish. Given this focus, These divisions can be read in a number of and the imperial history and subsequent multi- ways depending upon the context, and Barcan cultural reality of the Christian world, Barcan is always at pains to unravel this confused discusses not only Western bodies, but also tension underscoring the equally confused how this hegemonic Judeo-Christian paradigm Western attitude towards the body in relation of morality has informed post-settlement to various embodied practices. The role of this approaches to indigenous peoples, and fre- opening chapter, however, is to explore the quently racist hierarchies of morality and clothing-civilisation equation, and to introduce humanity. Thus it is only within this framework a number of key sites and debates within disthat non-Western bodies are discussed — that is, cussions of nakedness—ones which take as 
their starting point the acceptable borderlines around nakedness as in need of stringent management and policing.

As previously mentioned, the artistic 'nude' is, in particular, well-travelled terrain and thus furnishes us with much insight into the cultural myths that coalesce around desired and disfavoured forms of undress, and the gendering of nakedness. A quote from noted art historian John Berger neatly sums this up: 'Nakedness is imperfect and individual; the nude is ideal and universal. Nakedness is nature; nudity, culture.' (33) The figurative practices circumscribing the representations of the naked, generally female, form in art work to 'civilise' the otherwise primal, antisocial naked form. As commented upon later in the book in relation to policing public displays of the body, such an understanding of the pleasures of the unclad female wa form works within a larger ideological frame in which female nakedness is never as problematic for patriarchal Western society as that of beh men: women's bodies are expected sites of pleasurable display with a 'logical' connection to nature and nakedness; men's are (apparently) less aesthetically pleasing, and a site of greater physical and ideological threat. Barcan also discusses how striptease problematises nudity, revealing it to be a socially prescribed state, not an absolute description of an ahistorical truth:

Whatever else it may do, striptease actually problematizes nudity as much as simply revealing it. It reminds us, perhaps, that nakedness is not self-evidently the same as exposure, either experientially or conceptually. Bareness and nudity are not the same thing; bare flesh is not always naked. Can an elbow be nude? Or a face? What about bald heads? Or feet? We talk about 'bare' feet, but never about 'nude' or 'naked' feet; nor do we talk about a 'nude' head. Not all parts of the body can, it seems, be 'naked.' This is a cultural matter.

Commercial nudity designed for a male, heterosexual audience in such forms as striptease and pornography is in the author's research revealed to be a major determinant of women's body hair fashion, especially the fashioning of pubic hair. The hegemonic policing of preferred body hair patterning has for a while been a topic of critical concern, especially in the wake of second wave feminist concerns. What is especially noteworthy is Barcan's finding that in the relative absence of other guides to behaviour, the general consensus of her interviewees is that heterosexual women are largely influenced by their partner's wishes when it comes to the shaping and removal of pubic hair and that, in turn, their partner's tastes are derived substantially from what they see in tabloid magazines and pornography. As the author later goes on to note, this educational chain has even more potentially worrying repercussions when we consider the role played in Australia at least by censorship guidelines which require the airbrushing of women's pubic areas to remove the reality of such things as protruding labia, in favour of a 'cleaner', less 'offensive', more Barbie-like genitalia. 
Taking a different perspective on the out in specific instances. For example, Barcan complex binary divide around nudity in the addresses such things as modern depilation Judeo-Christian tradition, Chapter 2 explores practices as an exercise in turning 'nature' nakedness qua metaphor as a moral positive, (nakedness) into 'culture' (nudity); the role of not just as a negative or in relation to the state body hair, or more specifically its absence, as a of being dressed. Fundamental to this side of marker of grades of humanness (more hair, the coin is another seemingly age-old illus- more animal; less hair, more human), which tration: nakedness as a marker of purity. Arising has of course functioned to privilege whiteness; out of a metaphysical basis furnished by Judaic celebrity nakedness and the acceptability of and Greek traditions, two basic sets of naked- nudity for those considered beautiful and ness as a metaphor are identified: 'those associ- young, while applying a different standard for ated with presence (authenticity, truth, origins, others (witness the recent campaign by a British nature, simplicity) and those with absence tabloid to encourage Sarah Ferguson to keep (deprivation, degradation, vulnerability, ex- her clothes on and not appear nude in a charity posure, punishment)'. (83) Enabling this turn calendar); and the various meanings attached to of events is the idea that nakedness is a state we the exposed female breast-its heroic connecare capable of being 'in'-a state therefore of tion with courageous strong fighting women grace at times, not just an enforced process of (French revolutionary figures Liberty and absence. The author observes that discussions Marianne, Godiva, Artemis and the Amazons), of nudity frequently evoke the word 'in' ('in the and its maternally derived symbolic role as 'as nude'), as distinct from the prima facie perhaps fount of charity and nurturance'. (230) Chapter more obvious choice of 'out', given that being 3's discussion of the connections between nude is being outside of one's clothes. This nakedness and criminality and insanity appears denotes, she argues, nudity's status as some- particularly underdeveloped within the space thing worthy in its own right, as something afforded by the study (except in terms of the greater than the opposite of dress, a state which distinction between 'streaking' and 'flashing'), itself is uniquely culturally determined. Nudism and this reader was here left wanting a little bit as a movement emerges as an important site for more. Chapter 4, which sees a return to questhe embodied experience of nakedness, con- tions of images, is the most Australian-focused tentiously having to fight as it does to dis- of the chapters, employing as it does local associate itself from the conflation of nakedness examples to illustrate larger claims.

with sexuality to instead locate itself as a At the core of the author's stated intent in freely chosen choice to be in a state of a more writing Nudity was a desire to clearly establish pure 'nature'

'that nakedness too is a metaphor, and as social

Chapters 3 and 4 unravel further the various and cultural a phenomenon as clothing'. (57)

ways in which these complex understandings This she has no doubt achieved and, in so of nakedness, morality and power are played doing, made a valuable contribution to cultural 
studies of the body by actually mapping out what is, in its quotidian reality, an always encountered, but under-researched, understanding of our embodied experience. Nudity problematises some branches of cultural studies's focus upon representation at the expense of the greater messiness of lived, embodied experience. In so doing, it implicitly calls for more work to be undertaken into our quotidian bodily practices as they are lived by people everyday. However, in never being able to totally escape questions of representation, the study illustrates not only how individual and collective meanings are products of various mediations, but that cultural scholars need to always be attentive to the complex interplay between the two.

SUSAN LUCKMAN is a lecturer in the School of Communication, Information and New Media at the University of South Australia, and researches in communication, media and cultural studies. She is Secretary of the Cultural Studies Association of Australiasia (CSAA), and Co-Convenor of the Cultures of the Body Research Group. <http://people.unisa.edu.au/Susan.Luckman> 